\title{
STABLE INTERTROCHANTERIC FRACTURES OF FEMUR TREATED WITH MINIMALLY INVASIVE SLIDING HIP SCREW FIXATION - OUTCOMES, PEARLS AND PITFALLS
}

B. Sanjeev Reddy ${ }^{1}$, Sanjeevi Bharadwaj²

\section{HOW TO CITE THIS ARTICLE:}

B. Sanjeev Reddy, Sanjeevi Bharadwaj. "Stable Intertrochanteric Fractures of Femur Treated with Minimally Invasive Sliding Hip Screw Fixation - Outcomes, Pearls and Pitfalls". Journal of Evolution of Medical and Dental Sciences 2014; Vol. 3, Issue 46, September 22; Page: 11242-11248, DOI: 10.14260/jemds/2014/3466.

\begin{abstract}
BACKGROUND: The following prospective consecutive case series was done to evaluate indications, technical pearls and functional outcomes of minimally invasive sliding hip screw in the fixation of stable intertrochanteric fractures of femur. These fractures carry risks associated with prolonged immobilization for which, early fracture fixation and early ambulation of the patient is necessary. Sliding hip screw remains the most common method for the treatment of stable intertrochanteric fractures of femur. METHODS: A total of 80 patients (48 males, 32 females) with stable intertrochanteric fractures of femur were treated with minimally invasive sliding hip screw technique. Average age of the patients was 73 year. Average blood loss during surgery, reduction of postoperative haemoglobin, requirement of post-operative analgesics and total days of postoperative hospital stay were studied. RESULTS: Length of incision, operation time, blood loss and duration of hospital stay were significantly less. Mean operating time was 50 minutes. Mean intra-operative blood loss was $53 \mathrm{ml}$. Mean reduction of postoperative haemoglobin was $0.9 \mathrm{gm} / \mathrm{dl}$. Average wound size was of $5 \mathrm{~cm}$. The average follow-up was 17 months. The average postoperative analgesic requirement was twice daily for 5 days. Mean hospital stay after surgery was 5 days. CONCLUSION: Minimally invasive sliding hip screw is a novel and advantageous technique that can be used comfortably for the treatment of stable intertrochanteric fractures of femur, thus providing rigid fracture fixation and early mobilization of the patients. Thus, the judicial use of this technique significantly reduces the amount of blood loss, soft tissue dissection, requirement of post-operative analgesics and also the length of stay in the hospital.
\end{abstract}

KEYWORDS: Sliding Hip Screw, Intertrochanteric fractures, minimally invasive.

INTRODUCTION: Trochanteric fracture of femur is one of the commonest fractures in elderly people ${ }^{(1,2)}$ and carries risks associated with prolonged immobilization. Early ambulation of the patients reduces the complications, ${ }^{(1)}$ which is possible only in the presence of a rigid fixation of the fracture and a good post-operative analgesia. There are various methods of stable fixation such as sliding hip screw, intramedullary nail, trochanteric locking plate, fixed angle blade plate and dynamic condylar plate. $(1-3)$

Dynamic hip screw fixation remains one of the common methods of treatment in the treatment of stable intertrochanteric fractures.(4-6) Minimally Invasive Sliding Hip Screw (MISHS) fixation has advantages of less blood loss, minimal soft tissue dissection, lesser requirement of postoperative analgesics and shorter hospital stay.(6-8) This prospective study aimed to evaluate the outcomes, pearls and pitfalls of stable intertrochanteric fractures of femur treated with sliding hip screw fixation. 
METHODS: Between June 2012 and June 2014, 80 patients (48 male, 32 female) with closed stable intertrochanteric fractures of femur were admitted to our hospital. Patients were recruited according to a particular inclusion and exclusion criteria. All closed stable intertrochanteric fractures with AO (Arbeitsgemeinschaft fur Osteosynthesefragen) type A1.1 to A2.1 were included. Patients with polytrauma, pathological fracture, unstable intertrochanteric fracture with A0 type A2.2 to A3.3, compound fracture and failed closed reduction on fracture table were excluded.

Operation time, intraoperative technical problems, local complications and functional outcomes were analyzed. Intra operatively, blood loss was measured by weighing of blood soaked mops. Specific gravity of red corpuscles is 1.0293 and of plasma 1.0270 . Hence, $1 \mathrm{ml}$ of blood weighs 1gm. (9) Postoperatively, AP and lateral radiographs were obtained on the 1st postoperative day.

Follow ups with clinical examinations and radiological studies were performed on days 7 and 42, at 3 and 6 months. A standard protocol was followed for postoperative analgesia. For the first 24 hours, all the patients received injection Diclofenac $75 \mathrm{mg}$ intramuscular (deep gluteal) 8th hourly. After 24 hours, tablet Diclofenac $50 \mathrm{mg}$ was prescribed according to the patient's requirement. Postoperative haemoglobin was measured after 24 hours of surgery and its value was compared with preoperative haemoglobin.

SURGICAL PROCEDURE: All operations were performed under spinal anesthesia on fracture table. Fractures were reduced by closed manipulation under image intensifier. A guide wire mounted in 135 degree guide plate was placed over anterior aspect of hip and checked in image intensifier in AP view (Figure 1). Plate was aligned with the lateral border of femur and guide wire was aligned in lower half of femoral neck and head and confirmed on image intensifier (Figure 2) and the entry point of guide wire was marked in lateral aspect of thigh.

A $5 \mathrm{cms}$ of skin incision was made. Fascia lata and Vastus lateralis were incised by diathermy to minimize blood loss (Figure 3). Guide wire was inserted from lateral border of femur below $2.5 \mathrm{~cm}$ from trochanteric flair with the help of 135-degree angle guide. Correct placement of guide-wire was checked with image intensifier in AP and lateral views. Reaming was done with desired length. Hip screw was then inserted. Guide-wire was removed.

Four-hole barrel plate was inserted through the wound in such a way that barrel faces laterally (Figure 4). After inserting the plate it was turned 180-degree and introduced over hip screw (Figure 5). In obese patients difficulties in inserting the barrel on hip screw were made easy with reintroducing guide-wire through the barrel plate. Plate was then fixed with femur shaft with four cortical screws. Compression screw was inserted. Fascia and subcutaneous tissues were sutured with absorbable suture and skin was closed with staples. No drain was inserted.

Toe touch ambulation with a walker was started from the first postoperative day. Patients were discharged from hospital once they were well ambulated. Sutures were removed in two weeks. Partial weight bearing ambulation was started in three weeks and full weight bearing ambulation was started in an average of three months. The patients were followed up with AP and lateral radiographs at three weeks, six weeks, three months and six months. Duration for achieving radiological union was noted.

RESULTS: Eighty patients with stable intertrochanteric fracture were followed up for 6 months. There were 48 male patients and 32 female. Average age of the patients was 73 years (range: 60 
years to 86 years). Forty five fractures were on the right side and thirty five on the left. Mean operating time was 50 minutes (range: 40 to 60 minutes). Mean wound size was of $5 \mathrm{cms}$. Mean intraoperative blood loss was $53 \mathrm{ml}$ (range: 43 - $85 \mathrm{ml}$ ).

Mean reduction of postoperative haemoglobin was $0.9 \mathrm{gm} / \mathrm{dl}$ (range: 0.3 to $1.1 \mathrm{gm} / \mathrm{dl}$ ). Mean requirement of analgesics in postoperative period was for 5 days (range: 3 to 7 days). Mean requirement of analgesics in a day was two times (one to three times). Mean operating time was 50 min (range: 40 - $60 \mathrm{~min}$ ). Mean wound size was of $5 \mathrm{cms}$. Mean hospital stay after surgery was 5 days (4 to 6 days). The average follow-up was 17 months (range: 12to 24). No infection was observed. All fractures united within 3 months. There were no surgery related complications.

DISCUSSION: Sliding hip screw (SHS) with side plate assembly remains one of the most common methods for the treatment of intertrochanteric fracture of femur. This method provides rigid fixation and facilitates early mobilization of patients $(6,10)$. There are several studies with good results using Minimally Invasive Sliding Hip Screw (MISHS) for the treatment of stable intertrochanteric fracture of femur.

In MISHS, it has been found to have less intraoperative blood loss than with Conventional Sliding Hip Screw (CSHS). It is thought to be due to less soft tissue dissection, less fracture exposure and incision being in the safer vascular zone.(8,10,11) In our study amount of per-operative blood loss was $53 \mathrm{ml}$ (range: $43-85 \mathrm{ml}$ ). In the study of Di Paola et al(12) it was $41 \mathrm{ml}$. Little et al(13) found 160 $\mathrm{ml}$ of per-operative blood loss in CSHS.

Houet al(14) and Chua et al(15) had an average of $283 \mathrm{ml}$ and $409 \mathrm{ml}$ of per-operative blood loss respectively with CSHS. Reduction of postoperative haemoglobin was less in MISHS than in CSHS in comparative studies of Wong et $\mathrm{al}^{(6)}$, Ho et $\mathrm{al}^{(8)}$ and Wang et al.(11) Less blood loss reduces the requirement of its transfusion and minimizes cardiovascular complications.

Size of the incision is directly proportional to the intensity of the post-operative pain and incidence of surgical wound contamination. In all the 80 patients, the average incision size was $5 \mathrm{cms}$ which is comparable with the incision size of Ho et al.(8) Wong et al(6) and Alobaid et al(7) had wound size of $2.5 \mathrm{cms}$ and Walia et al(16) had of $3 \mathrm{cms}$. In the study conducted by Ho et al, the incision size in CSHS was of $15 \mathrm{cms}$.

To minimize the size of the incision, all the patients were treated using SHS with four-hole barrel plate. Alobaid et al(7) and Walia et al(16) used SHS with two-hole barrel plate and concluded that using SHS with two-hole barrel plate by minimally invasive technique gives equally good results as a regular SHS done with a longer incision and plate in stable intertrochanteric fractures. ${ }^{(17)}$

Patients were given $75 \mathrm{mg}$ of intramuscular injection of Diclofenac eight hourly in postoperative period for 24 hours followed by tablet Diclofenac $50 \mathrm{mg}$ in oral form as per the patient's requirements with a maximum of three times a day. Average requirement of tablet Diclofenac in postoperative period was 10 tablets.

Average total days of analgesic required were five days. Wong et al(6) in their study found that the amount of postoperative analgesic required were $8.6 \mathrm{mg}$ of pethidine and 5.4 tablets in MISHS whereas $48.4 \mathrm{mg}$ of pethidine and 8.6 tablets in CSHS. They concluded the requirement of postoperative analgesics were significantly less in MISHS than CSHS. Similarly in the study by Alobaid et al(7) patients required $15.1 \mathrm{mg}$ of Morphine, $169 \mathrm{~g}$ of Codeine and $1.9 \mathrm{~g}$ of Acetaminophen as postoperative analgesics in MISHS group whereas $25.2 \mathrm{mg}$ of Morphine, $209 \mathrm{~g}$ of Codeine and $5.4 \mathrm{~g}$ of 
Acetaminophen in CSHS group. Lee et al (10) found that the length of hospital stay after surgery was 5.4 days in MISHS group and 8.8 days in CSHS group. Wang et al(11) had 5.7 days of postoperative length of hospital stay in MISHS and 7.9 days in CSHS groups.

Ho et al(8) found that the average length of hospital stay of patients in MISHS group was 12.1 days and in CSHS group was 23.3 days. In this case series, average length of postoperative hospital stay was 5 days which is similar to the studies of Lee et al(10) and Wang et al(11). Improved postoperative analgesia and early ambulation of the patient not only decreases the chances of postoperative complications but also shortens the period of hospital stay and reduces the cost of the treatment significantly.

CONCLUSION: Minimal Invasive Sliding hip screw (MISHS) is a novel, comfortable and advantageous technique that can be used for the treatment of stable intertrochanteric fractures of the femur, thus providing rigid fracture fixation and in turn, early mobilization of the patients. Thus, the judicial use of this technique significantly reduces the amount of blood loss, soft tissue dissection, requirement of post-operative analgesics and also the period of hospital stay.

\section{REFERENCES:}

1. Kyle RF, Gustilo RB, Premer RF. Analysis of six hundred and twenty-two intertrochanteric hip fractures. J Bone Joint Surg Am. 1979; 61(2): 216-21.

2. LaVelle DG. Fractures of hip. In: Canale ST, editor. Campbell's operative orthopaedics. Philadelphia, PA, USA: Mosby/Elsevier; 2008. p. 2873-938.

3. Dhamangaonkar AC, Joshi D, Goregaonkar AB, Tawari AA. Proximal femoral locking plate versus dynamic hip screw for unstable intertrochanteric femoral fractures. J Orthop Surg (Hong Kong). 2013; 21(3): 317-22.

4. Bolhofner BR, Russo PR, Carmen B. Results of intertrochanteric femur fractures treated with a 135-degree sliding screw with a two whole side plate. J Orthop Trauma. 1999; 13(1): 5-8.

5. Zuckerman JD, Skovron ML, Koval KJ, Aharonoff G, Frankel VH. Postoperative complications and mortality associated with operative delay in older patients who have a fracture of the hip. J Bone Joint Surg Am. 1995; 77: 1551-6.

6. Wong TC, Chiu Y, Tsang WL, Leung WY, Yeung SH. A double-blind, prospective, randomized, controlled clinical trial of minimally invasive dynamic hip screw fixation of intertrochanteric fractures. Injury. 2009; 40(4): 422-27.

7. Alobaid A, Harvey EJ, Elder GM,Lander P, Guy P, Reindl R. Minimally invasive dynamic hip screw: prospective randomized trial of two techniques of insertion of a standard dynamic fixation device. J Orthop Trauma. 2004; 18(4): 207-12.

8. Ho M, Garau G, Walley G, Oliva F, Panni AS, Longo UG, Maffulli N. Minimally invasive dynamic hip screw for fixation of hip fractures. Int Orthop. 2009; 33(2): 555-60.

9. Thomton JA. Estimation of blood loss during surgery. Ann R Coll Surg Engl. 1963 Sep; 33(3): 164-74.

10. Lee YS, Huang HL, Lo TY, Huang CR. Dynamic hip screw in the treatment of intertrochanteric fractures: a comparison of two fixation methods. Int Orthop. 2007; 31(5): 683-88.

11. Wang JP, Yang TF, Kong QQ, Liu SJ, Xiao H, Liu HZ. Minimally invasive technique versus conventional technique of dynamaic hip screw for intertrochanteric femoral fractures. Orthop Trauma Surg. 2010; 130(5): 613-20. 


\section{ORIGINAL ARTICLE}

12. DiPaola M, Rozbruch SR, Helfet DL. Minimal incision technique using a two-hole plate for fixation of stable intertrochanteric hip fractures. Orthopaedics. 2004; 27: 270-74.

13. Little NJ, Verma V, Fernando C, Elliott DS, Khaleel A. A prospective trial comparing the Holland nail with the dynamic hip screw in the treatment of intertrochanteric fractures of the hip. J Bone Joint Surg Br. 2008 Aug; 90(8): 1073-78.

14. Hou GJ, Zhou F, Zhang ZS, Ji HQ, Tian Y. Analysis of the blood loss in perioperative period of femoral intertrochanteric fractures in old patients treated with different internal fixations. Beijing DaXueXue Boa. 2013 Oct 18; 45(5): 738-41.

15. Chua YP, Kwan MK, Saw A. Operative treatment of trochanteric fractures with dynamic hip screw - is perioperative blood transfusion needed? Med J Malaysia. 2005 Jul; 60C: 78-82.

16. Walia JPS, Gupta AC, Singh M, Walia SK, Singh S. Pb J Orthop. 2010; 12(1): 12-13.

17. McLoughlin SW, Wheeler DL, Rider J, Bolhofner B (2000). Biomechanical evaluation of the dynamic hip screw with two- and four-hole side plates. J Orthop Trauma.2000; 14: 318-23.

A guide wire mounted in 135 degree guide plate was placed over anterior aspect of hip and checked in image intensifier in AP view

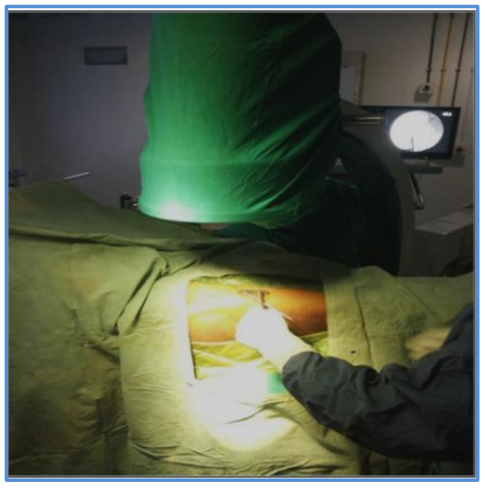

FIGURE - 1

Plate was aligned with the lateral border of femur and guide wire was aligned in lower half of femoral neck and head and confirmed on image intensifier

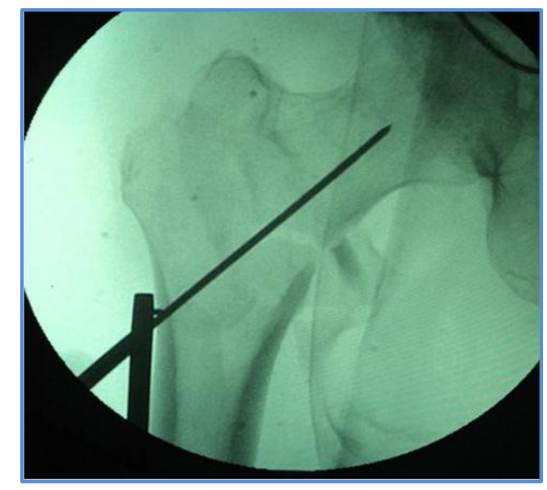

FIGURE - 2 


\section{ORIGINAL ARTICLE}

Entry point for the guide wire

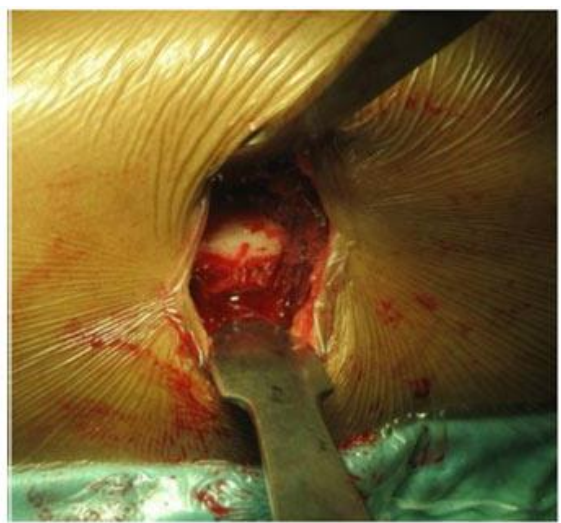

FIGURE - 3

Insertion of the barrel plate

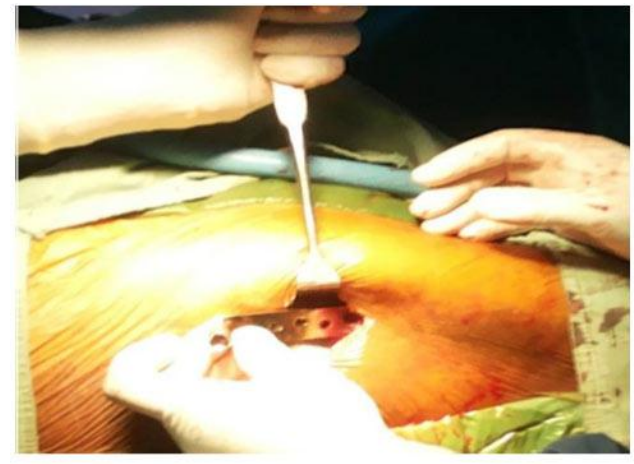

FIGURE - 4

Insertion of blade plate over hip screw

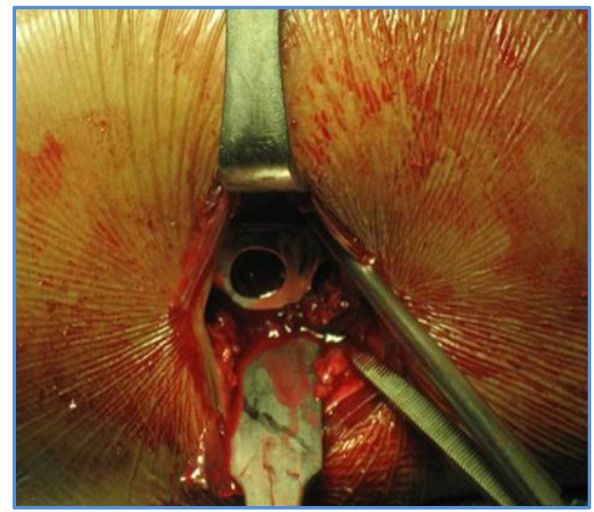

FIGURE - 5 


\section{ORIGINAL ARTICLE}

Postoperative X-ray

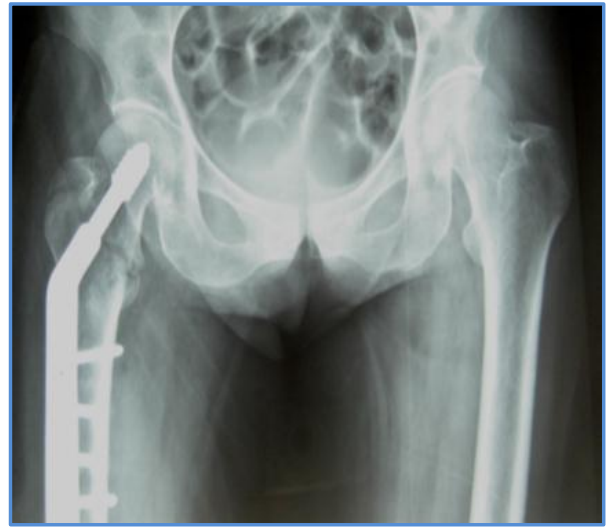

FIGURE - 6

\section{AUTHORS:}

1. B. Sanjeev Reddy

2. Sanjeevi Bharadwaj

\section{PARTICULARS OF CONTRIBUTORS:}

1. Professor \& HOD, Department of Orthopaedics, Mahadevappa Rampure Medical College, Gulbarga, Karnataka.

2. Resident Post Graduate, Department of Orthopaedics, Mahadevappa Rampure Medical College, Gulbarga, Karnataka.

\section{NAME ADDRESS EMAIL ID OF THE} CORRESPONDING AUTHOR:

Dr. Sanjeevi Bharadwaj, 28/1, Eswari Flats, $2^{\text {nd }}$ Street, Parameswari Nagar, Adyar, Chennai-600020, Tamil Nadu, India.

Email: drsanjeevibharadwaj@gmail.com

Date of Submission: 06/09/2014. Date of Peer Review: 08/09/2014. Date of Acceptance: 15/09/2014. Date of Publishing: 20/09/2014. 